\title{
Data on the Corrosion Resistance and Polarization Behaviour of Lean Austenitic and Ferritic Stainless Steels in Neutral Chloride Media
}

\author{
ROLAND TOLULOPE LOTO* \\ Department of Mechanical Engineering, Covenant University, Ota, Ogun State, Nigeria. \\ ${ }^{*}$ Corresponding author E-mail: tolu.loto @ gmail.com \\ http://dx.doi.org/10.13005/ojc/350330
}

(Received: February 28, 2019; Accepted: June 09, 2019)

\begin{abstract}
Stainless steels are extensively applied in diverse industries due to their exceptional corrosion resistance. The corrosion resistance of alloy stainless steels (316 L austenitic and 430Ti ferritic stainless steel) was studied in neutral chloride solutions with chloride concentrations of $1 \%, 2 \%, 3 \%$, $4 \%, 5 \%$ and $6 \%$. Their general and localized corrosion resistance were compared and discussed in addition to their passivation characteristics. Corrosion rate results obtained showed 430Ti exhibited slightly greater general resistance to chloride attack compared to $316 \mathrm{~L}$. Further investigation showed 316 L steel exhibited higher resistance to localized corrosion attack to its resilient passive film. 430Ti exhibited cathodic and anodic passivation compared to $316 \mathrm{~L}$ which only exhibited anodic passivation. Optical microscopic analysis showed the presence of small, superficial corrosion pits on $316 \mathrm{~L}$ steel compared to $430 \mathrm{Ti}$, which exhibited deep corrosion pits.
\end{abstract}

Keywords: Corrosion, Ferritic Stainless Steels, Pitting, $\mathrm{NaCl}$.

\section{INTRODUCTION}

Corrosion of stainless steel in reducing/ oxidizing environments is a major problem of global and industrial significance due to the secondary problems associated with it $^{1,2}$. Stainless steels displays enhanced corrosion resistance properties in conditions destructive to carbon steels due to the presence of chromium and other alloying elements. chromium chemically combines with $\mathrm{O}_{2}$, to form an impenetrable oxide, which protects the alloy from chloride and other aggressive anions. The nature of the protective oxide formed on stainless steels is the product of the metallurgical structure and phase constituents of the steel. Breakdown of the passive film in the presence of chlorides and the resulting localized corrosion is one of the important factors responsible for failure of stainless steels ${ }^{3-7}$. Chloride anion containing environments are usually encountered during application of stainless steels in industries such as marine/shipping, oil and gas production, power generating plants, industrial plants located along seacoast, oil field water injection and desalination plants. Corrosion problems associated with stainless steels within these environments is responsible for catastrophic failures, plant shutdown,

This is an Open Access article licensed under a Creative Commons license: Attribution 4.0 International (CC- BY). Published by Oriental Scientific Publishing Company @ 2018 
high maintenance cost and increase in sales cost to end users. The inherent instability of stainless steels in their refined forms is the basic cause of their corrosion as they tend to revert to their natural states through interaction with corrosive anions in their environment of application. Differential concentrations of chlorides have been known to reduce the operating lifespan of stainless steels ${ }^{6,8-9}$. It must be noted that appropriate selection of stainless steels with respect to corrosivity and composition of the operating environment is one of the major factors sustaining the viability of steels in service though in many cases corrosion inhibitors are applied ${ }^{10,11}$. The focus given to material selection has increased over the years ${ }^{12}$. Corrosion resistance of stainless steels vary with respect to general and localized corrosion as a result of the fundamental property of the electrochemical processes involved and the nature of the corrosive environment ${ }^{13}$. Application of stainless steels in operating conditions where they are most effective is very important. This research studies and compares the general and localized corrosion resistance of $316 \mathrm{~L}$ austenitic and 430 Ti ferritic stainless steels in varying concentrations of chloride in neutral chloride environment.

\section{EXPERIMENTAL}

316 L austenitic (316L) and 430Ti ferritic (430Ti) stainless steel specimen plates were cut to average dimensions of $1 \mathrm{~cm}$ by $1 \mathrm{~cm}$ rod with manual hack saw. The specimens were encased in resin mounts and metallographically prepared using emery papers of $80,120,220,800$ and 1000 grits. They were subsequently polished with 6 um diamond paste for polarization test. Neutral chloride solution as prepared in volumetric concentration of $1 \%, 2 \%, 3 \%, 4 \%, 5 \%$ and $6 \% \mathrm{NaCl}$ concentration from analar grade $\mathrm{NaCl}$ in distilled $\mathrm{H}_{2} \mathrm{O}$ at 200 $\mathrm{mL}$ each. Potentiodynamic polarization test was performed with Digi-Ivy 2300 potentiostat at $25^{\circ} \mathrm{C}$ ambient temperature. Resin mounted $316 \mathrm{~L}$ and 430Ti stainless steel electrodes with surface area of $1 \mathrm{~cm}^{2}$, Pt counter electrode and silver chloride reference electrode $(\mathrm{Ag} / \mathrm{AgCl})$ were immersed in $100 \mathrm{~mL}$ of the chloride test solution and connected to the potentiostat. Potentiodynamic measurement was performed from $-1.5 \mathrm{~V}$ to $1.5 \mathrm{~V}$ at a scan rate of $0.0015 \mathrm{~V} / \mathrm{s}$. Omax metallurgical microscope was employed to visualize and capture images of the mounted steel before corrosion and after corrosion test. The corrosion current density $\left(I_{\text {corr }}\right)$ and corrosion potential $\left(\mathrm{E}_{\text {corr }}\right)$ were calculated from the Tafel plots of potential versus log current. The corrosion rate $(\delta)$ was determined from equation 1 .

$$
\delta=\frac{0.00327 \times I_{\operatorname{corr}} \times E_{\mathrm{q}}}{D}
$$

Where $\mathrm{I}_{\text {corr }}$ is the current density in $\mu \mathrm{A} / \mathrm{cm}^{2}, \rho$ is the density in $\mathrm{g} / \mathrm{cm}^{3} ; \mathrm{E}_{\mathrm{q}}$ is the specimen equivalent weight in grams. 0.00327 is a constant for corrosion rate calculation in $\mathrm{mm} / \mathrm{y}$.

Polarization resistance $\left(R_{p}\right)$ was determined from the equation below;

$$
R_{\mathrm{p}}=2: 303 * \mathrm{BaBc} / \mathrm{Ba}+\mathrm{Bc}\left[1 / \mathrm{I}_{\text {corr }}\right]
$$

Where $\mathrm{B}_{\mathrm{a}}$ is the anodic Tafel slope and $\mathrm{B}_{\mathrm{c}}$ is the cathodic Tafel slope, both are measured as ( $\mathrm{V}$ vs $\mathrm{Ag} / \mathrm{AgCl} / \mathrm{dec}$ ). Optical microscopic images were produced from captured images of the steel morphology before and after the electrochemical tests.

\section{RESULTS AND DISCUSSION}

\section{Potentiodynamic polarization studies}

Tables 1 and 2 shows the data obtained from the potentiodynamic polarization tests for $316 \mathrm{~L}$ and 430Ti stainless steels. Fig. 1 and 2 shows the polarization curves of $316 \mathrm{~L}$ and $430 \mathrm{Ti}$ obtained from the tests. The corrosion rates of $316 \mathrm{~L}$ were generally higher than the values obtained for 430Ti in the neutral chloride solution at specific $\mathrm{NaCl}$ concentrations $(1 \%-6 \% \mathrm{NaCl})$. This observation is due to the higher tendency of $316 \mathrm{~L}$ valence atoms to oxidize than $430 \mathrm{Ti}$ in the presence of chlorides. While the corrosion resistance of $316 \mathrm{~L}$ is proportional to $\mathrm{NaCl}$ concentration, the corrosion rate value of 430Ti bears no proportional relationship signifying greater general corrosion resistance as earlier mentioned. At $1 \% \mathrm{NaCl}, 316 \mathrm{~L}$ has a corrosion rate of $0.076 \mathrm{~mm} / \mathrm{y}$ which corresponds to $7.33 \times 10^{-6}$ $\mathrm{A} / \mathrm{cm}^{2}$. Increase in $\mathrm{NaCl}$ concentration caused the corrosion rate to increase, peaking at $0.129 \mathrm{~mm} / \mathrm{y}$ at $6 \% \mathrm{NaCl}$ concentration. Changes in the anodiccathodic Tafel values couples with the active-passive transition of the corrosion potentials shows the redox reaction mechanism responsible for corrosion counterbalances each other. However, observation of the polarization plots in Fig. 1 shows at $1 \% \mathrm{NaCl}$ concentration the mechanism of $\mathrm{H}_{2}$ evolution/ 
$\mathrm{O}_{2}$ reduction reactions were partially restrained. Beyond $1 \% \mathrm{NaCl}$, the intensity of reduction reactions increased as shown from the absence of cathodic passivation. It must be noted that the presence of higher chloride atoms caused double anodic-cathodic peaks at some concentrations. Secondly higher chloride concentration extended the passivation range of the polarization plots after $1 \% \mathrm{NaCl}$ before breakdown at the transpassive region. The corrosion rate values observed for $430 \mathrm{Ti}$ indicates a generally more stable passive film, though it does not necessarily constitute higher resistance to localized corrosion. However, the polarization plots in Fig. 2 confirm the results in Table 2. The plots show anodic and cathodic passivation behaviour at all concentrations studied before the intercept at corrosion potential. Cathodic passivation limited the hydrogen evolution and oxygen reduction reactions while anodic passivation stifled the surface oxidation of the steel. This observation is confirmed from the anodic-cathodic Tafel values in Table 2 whose variation tends to transition more smoothly at lower values compared to Table 1.

Table 1: Potentiodynamic polarization data on for $316 \mathrm{~L}$ in neutral choride $(1 \%-6 \% \mathrm{NaCl}$ concentration) solution

\begin{tabular}{|c|c|c|c|c|c|c|c|c|}
\hline A & 1 & 0.076 & 7.33E-06 & 7.33E-06 & -0.436 & 3505.00 & -4.274 & 2.525 \\
\hline B & 2 & 0.086 & $8.22 \mathrm{E}-06$ & $8.22 \mathrm{E}-06$ & -0.855 & 3370.00 & -11.030 & 2.620 \\
\hline$E$ & 5 & 0.115 & $1.11 \mathrm{E}-05$ & 1.11E-05 & -0.901 & 2321.00 & -11.130 & 1.644 \\
\hline $\mathrm{F}$ & 6 & 0.129 & $1.24 \mathrm{E}-05$ & $1.24 \mathrm{E}-05$ & -0.874 & 2074.00 & -9.445 & 1.754 \\
\hline
\end{tabular}

Table 2: Potentiodynamic polarization data on for $430 \mathrm{Ti}$ in neutral chloride $(1 \%-6 \% \mathrm{NaCl}$ concentration) solution

\begin{tabular}{|c|c|c|c|c|c|c|c|c|}
\hline$A$ & 1 & 0.048 & 4.51E-06 & 4.51E-06 & -0.424 & 5245.00 & -3.020 & 5.026 \\
\hline B & 2 & 0.036 & 3.33E-06 & 3.33E-06 & -0.399 & 7723.00 & -3.724 & 5.285 \\
\hline$E$ & 5 & 0.044 & 4.06E-06 & 4.06E-06 & -0.281 & 6314.00 & -4.015 & 4.313 \\
\hline $\mathrm{F}$ & 6 & 0.038 & 3.58E-06 & 3.58E-06 & -0.356 & 7175.00 & -5.295 & 4.934 \\
\hline
\end{tabular}

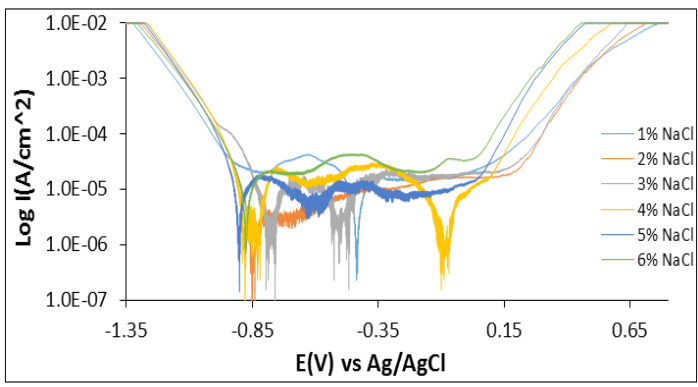

Fig. 1. Potentiodynamic polarization plot of $316 \mathrm{~L}$ corrosion in in neutral chloride $(1 \%-6 \% \mathrm{NaCl}$ concentration) solution

\section{Optical microscopy analysis}

Figure $3(a)$ and (b) shows the morphology of $316 \mathrm{~L}$ and 430Ti before corrosion at mag. x 100.

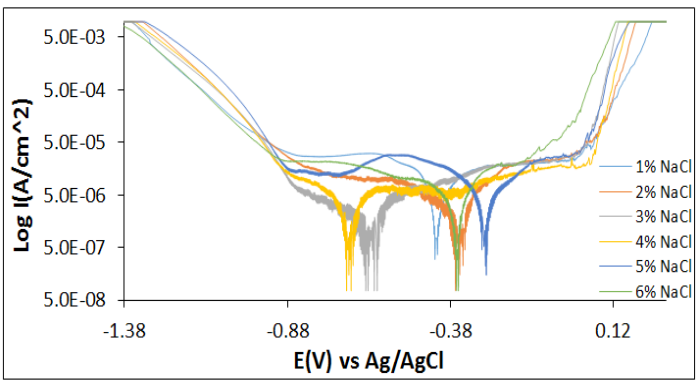

Fig. 2. Potentiodynamic polarization plot of 430Ti corrosion in in neutral chloride ( $1 \%-6 \% \mathrm{NaCl}$ concentration) solution

Fig. 4(a) and (b) shows the morphology of $316 \mathrm{~L}$ after corrosion from $1 \%$ and $6 \% \mathrm{NaCl}$ test solution, while Fig. 5(a) and (b) shows the morphology 
of $430 \mathrm{Ti}$ after corrosion from $1 \%$ and $6 \% \mathrm{NaCl}$ test solution. Observation of Fig. 4(a) shows the presence of corrosion pits associated with localized corrosion reactions on the steel surface. However, the pits appear superficial with little morphological alteration of the steel. On Fig. 4(b), the pits have disappeared due to the presence of excess chloride ions which generally oxidized the entire steel surface. Secondly, there is possibility that the excess chloride concentration reduced its oxidizing strength hence stifling its ability to displace the $\mathrm{O}_{2}$ atoms chemically combined with chromium. Observation of Fig. 5(a) and (b) shows fewer but deeper corrosion pits are visible on the surface of 430Ti signifying greater vulnerability to pitting corrosion. Increase in chloride concentration to $6 \%$ did not change the morphology of the steel except to slightly wear it due to increased redox reaction processes on the steel's surface. Comparing the results from the polarization test with the morphological observations, it is evident that $316 \mathrm{~L}$ is more resistant to localized corrosion reactions than $430 \mathrm{Ti}$, while $430 \mathrm{Ti}$ displays greater resistance general surface corrosion than $316 \mathrm{~L}$.

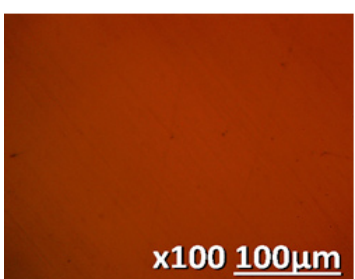

(a)

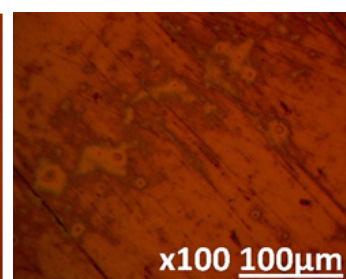

(b)
Fig. 3. Optical microscopy image at mag. $x 100$ before corrosion test (a) $316 \mathrm{~L}$ and (b) $430 \mathrm{Ti}$

\section{CONCLUSION}

430T9i ferritic stainless steel exhibited higher resistance to general corrosion compared to $316 \mathrm{~L}$ austenitic stainless steel. The polarization plots of 430Ti displayed cathodic and anodic paeeivation regions due to suppression of the redox electrochemical processes. However, 316L austenitic steel proves to be more resistant to localized corrosion reactions compared to $430 \mathrm{Ti}$
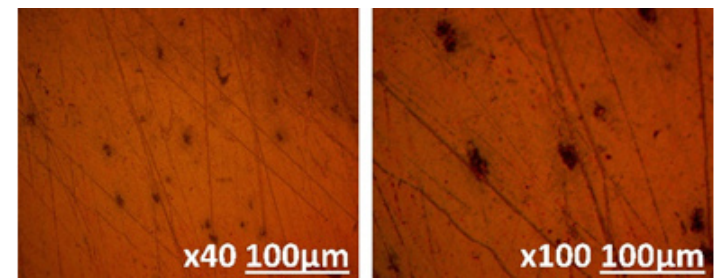

(a)
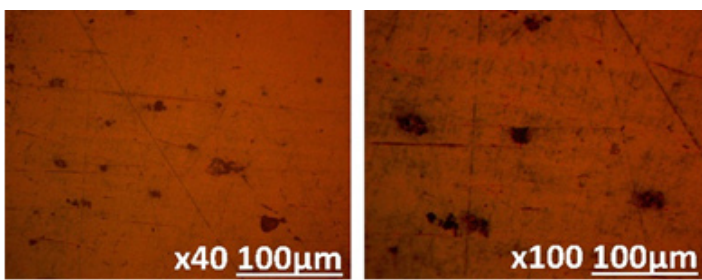

(b)

Fig. 5. Optical microscopy image of 430 Ti morphology after corrosion in (a) $1 \% \mathrm{NaCl}$ solution and (b) $6 \% \mathrm{NaCl}$ solution
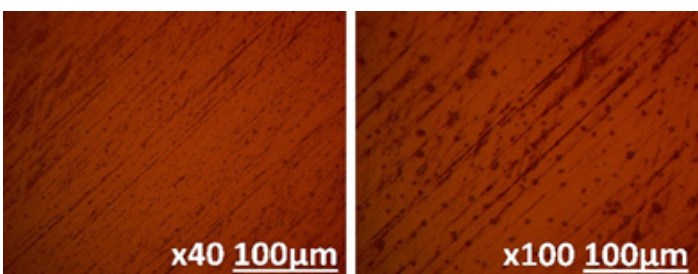

(a)
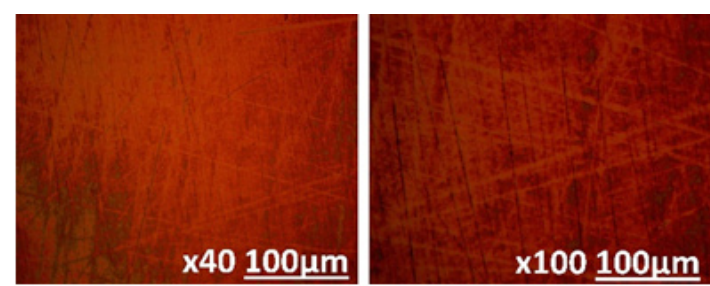

(b)

Fig. 4. Optical microscopy image of 316L morphology after corrosion in (a) $1 \% \mathrm{NaCl}$ solution and (b) $6 \% \mathrm{NaCl}$ solution

ferritic steel. This was supported by images from optical microscopy analysis.

\section{ACKNOWLEDGEMENT}

The authors sincerely appreciate Covenant University for the provision of research facilities and funding for publication.

\section{Conflict of interest}

Authors declare no conflict of interest

\section{REFERENCES}

1. Loto, R.T.; Loto, C.A. J. Mater. Res. Technol., 2018, 7(3), 231-239.
2. Abdallah, M. Mater. Chem. Phys., 2003, 82, 786-792. 
3. McCafferty, E. Corros. Sci., 2003, 45, 14211438.

4. Abdel Rehim, S.S.; Hassan, H.H.; Amin, M.A. Corros. Sci., 2004, 46, 1921-1938.

5. Loto, R.T.; Loto, C.A. J Fail. Anal. \& Preven., 2017, 17(4), 672-679.

6. Loto, R.T.; Loto, C.A. J. Mater. Res. Technol., 2017. doi.org/10.1016/j.jmrt., 2017, 07, 004.

7. Loto, R.T. J. Mater. Environ. Sci., 2013, 4(4), 448-459.

8. Fong-Yuan M. Corrosive effects of chlorides on metals Pitting corrosion. Intech Open., 2012, 139-78.

9. Oliver, DC.; Sephton, M. J. South Afr. Inst. Mineral Metall., 2003, 103(2), 93-100.

10. Loto, R.T. Results Phys., 2017, 7, 769-76.

11. Loto, R.T. S. Afr. J. Chem., 2017, 24, 148-55.

12. Strategic impact and cost of corrosion damage, http://www.corrosion-doctors.org/Why-Study/ Strategic-Impact.htm. [Retrieved: 30/03/2017].

13. Loto, R.T. Orient. J. Chem., 2017, 33(3), 1090-1096. 